\title{
Phospholipid-induced silk fibroin hydrogels and their potential as cell carriers for tissue regeneration
}

\author{
Chavee Laomeephol $^{1,2}$ | Marta Guedes ${ }^{3,4}$ | Helena Ferreira ${ }^{3,4}$ | Rui L. Reis ${ }^{3,4,5}$ | \\ Sorada Kanokpanont ${ }^{1,2,6}$ | Siriporn Damrongsakkul ${ }^{1,2,6}$ | Nuno M. Neves ${ }^{3,4,5}$ (i)
}

\footnotetext{
${ }^{1}$ Biomedical Engineering Program, Faculty of Engineering, Chulalongkorn University, Bangkok, Thailand

${ }^{2}$ Biomaterial Engineering for Medical and Health Research Unit, Faculty of Engineering, Chulalongkorn University, Bangkok, Thailand

${ }^{3}$ 3B's Research Group, I3Bs-Research Institute on Biomaterials, Biodegradables and Biomimetics, University of Minho, Headquarters of the European Institute of Excellence on Tissue Engineering and Regenerative Medicine, Guimarães, Portugal

${ }^{4}$ ICVS/3B's-PT Government Associate Laboratory, Braga/Guimarães, Portugal

${ }^{5}$ The Discoveries Centre for Regenerative and Precision Medicine, Headquarters at University of Minho, Guimarães, Portugal

${ }^{6}$ Department of Chemical Engineering, Faculty of Engineering, Chulalongkorn University, Bangkok, Thailand
}

\section{Correspondence}

Siriporn Damrongsakkul, Biomedical Engineering Program, Faculty of Engineering, Chulalongkorn University, Bangkok, Thailand. Email: siriporn.d@chula.ac.th

Nuno M. Neves, 3B's Research Group, I3BsResearch Institute on Biomaterials,

Biodegradables and Biomimetics, University of Minho, Headquarters of the European Institute of Excellence on Tissue Engineering and Regenerative Medicine, Guimarães, Portugal. Email: nuno@i3bs.uminho.pt

\section{Funding information}

The 100th Anniversary Chulalongkorn University Fund, Grant/Award Number: PhD grant; The 90th Anniversary Chulalongkorn University Fund (Ratchadaphiseksomphot Endowment Fund), Grant/Award Number: PhD grant; Chulalongkorn Academic Advancement into Its 2nd Century (CUAASC); REMIX Project, Grant/ Award Number: 778078; Fundação para a Ciência e a Tecnologia, Grant/Award Numbers: $\mathrm{PD} / \mathrm{BD} / 113795 / 2015$ and PTDC/CTM-BIO/ 4388/2014; Norte 2020, Grant/Award Number: NORTE 2020 Structured Project

\begin{abstract}
Silk fibroin (SF) hydrogels can be obtained via self-assembly, but this process takes several days or weeks, being unfeasible to produce cell carrier hydrogels. In this work, a phospholipid, namely, 1,2-dimyristoyl-sn-glycero-3-phospho-(1'-rac-glycerol) sodium salt (DMPG), was used to induce and accelerate the gelation process of SF solutions. Due to the amphipathic nature and negative charge of DMPG, electrostatic and hydrophobic interactions between the phospholipids and SF chains will occur, inducing the structural transition of SF chains to the beta sheet and consequently a rapid gel formation is observed (less than $50 \mathrm{~min}$ ). Moreover, the gelation time can be controlled by varying the lipid concentration. To assess the potential of the hydrogels as cell carriers, several mammalian cell lines, including L929, NIH/3T3, SaOS-2, and CaSki, were encapsulated into the hydrogel. The silk-based hydrogels supported the normal growth of fibroblasts, corroborating their cytocompatibility. Interestingly, an inhibition in the growth of cancer-derived cell lines was observed. Therefore, DMPG-induced SF hydrogels can be successfully used as a 3D platform for in situ cell encapsulation, opening promising opportunities in biomedical applications, such as in cell therapies and tissue regeneration.
\end{abstract}

\section{KEYWORDS}

cell encapsulation, cytocompatibility, DMPG, gelation time, hydrogel, silk fibroin

\section{1 | INTRODUCTION}

Hydrogels have been employed in numerous biomedical applications, namely, as scaffolds (Rossi, Santoro, \& Perale, 2015) and controlled release systems (Grijalvo, Mayr, Eritja, \& Díaz, 2016). Additionally, hydrogels can be used as 3D cell culture models to study the cellular behaviour or optimize the dose of pharmacological-based therapies
(Ding et al., 2018). Hydrogel networks contain a high content of water and a porous structure, allowing the exchange of gas, nutrients, biomolecules, and waste with their surrounding environment. Therefore, these systems mimic some of the characteristics of the extracellular matrix of many tissues, making them suitable platforms for cell encapsulation in tissue repair strategies (Peppas, Hilt, Khademhosseini, \& Langer, 2006). 
Several natural polymers have been used to produce cell encapsulation matrices, such as collagen, gelatin, and agarose (Mano et al., 2007; Ravi, Paramesh, Kaviya, Anuradha, \& Solomon, 2015). However, their use is limited, due to low mechanical stability and fast degradation (H. Lee et al., 2018). Synthetic materials can be used to overcome these drawbacks, but some disadvantages, such as a less affinity with biological systems, also limit their utilization (J. Lee, Cuddihy, \& Kotov, 2008). Silk fibroin (SF) is a natural polymer of choice for 3D cell culture, due to its unique properties, such as biocompatibility, excellent mechanical properties, tunable degradation, and versatility of its processing (e.g., hydrogels, films, fibres, and microparticles; Altman et al., 2003). SF is a naturally derived protein that can be produced by many silkworm species. Bombyx mori silkworm cocoons occupies a prominent position, due to their historic use in the textile industry and in the medical field (Naskar, Barua, Ghosh, \& Kundu, 2014). The polypeptides of SF are composed mainly by two different peptide chains, a heavy $(\sim 350 \mathrm{kDa})$ and a light $(\sim 25 \mathrm{kDa})$ fraction, chemically linked by a disulphide bridge. The heavy chains consist of characteristic repetitive hydrophobic oligopeptides interspersed by amorphous hydrophilic regions (Zhou et al., 2001). The repetitive sequences are responsible for the formation of thermodynamically stable structures through hydrophobic interactions and hydrogen bonding. In solution, SF gradually undergoes structural transitions from the unordered structure to the beta sheet conformer, leading to gel formation. This process can occur during several days or weeks, depending on the protein concentration and temperature (Ayub, Arai, \& Hirabayashi, 1993; Matsumoto et al., 2006; Nagarkar, Nicolai, Chassenieux, \& Lele, 2010). Therefore, a number of methods have been employed to accelerate this natural gelation process. Physical methods, such as $\mathrm{pH}$ reduction (Matsumoto et al., 2006; Nagarkar et al., 2010), vortex (Yucel, Cebe, \& Kaplan, 2009), and sonication (Wang, Kluge, Leisk, \& Kaplan, 2008) can effectively stimulate and enhance SF gelation. Similarly, many chemicals can also initiate SF structural transitions, for example, polyethylene oxide (Kim et al., 2004), poloxamer (Kang et al., 2000), polyethylene glycol (Wang et al., 2015), surfactants (Park et al., 2014; Wu et al., 2012; Zhang et al., 2015), and neutral-charged carbohydrate-based sophorolipids (Dubey, Nawale, Sarkar, Nisal, \& Prabhune, 2015). Although physical strategies allow a controllable gelation time and good biocompatibility, the requirement of equipment (e.g., probe sonicator or vortex) may be inconvenient for some clinical requests. Therefore, the use of chemical additives is a more interesting alternative, since the gelation occurs by a simple mixing of the SF solution with the chemical inducers under mild conditions. Additionally, the kinetics of hydrogel formation can be optimized to a desired period. A key property that needs to be considered in the development of those mixtures for biomedical purposes is their cytocompatibility and biocompatibility. The SF hydrogel formation induced by sophorolipids present a good cytocompatibility but a longer gelation time (approximately 140-180 min; Dubey et al., 2015). By using anionic surfactants, such as sodium dodecyl sulfate (Wu et al., 2012) and sodium N-lauroyl sarcosinate (Zhang, Jiaojiao, et al., 2015), the gelation is controllable by varying the chemical concentration. However, the cytocompatibility of this type of hydrogels needs to be investigated for longer periods of time. To attain these two compromises (tunable gelation time and cytocompatibility), we explored a new chemical additive to induce SF hydrogels formation.

Phosphorylglycerols (PGs), negatively charged amphipathic lipids, are biologically important as pulmonary surfactants in mammals and as membrane components in microorganisms (Buckland \& Wilton, 2000). PGs possess ability to induce conformational changes in several water-soluble proteins, such as a-lactalbumin (Bañuelos \& Muga, 1996), $\beta$-lactoglobulin (X. Zhang \& Keiderling, 2006), and physiological proteins (e.g., trypsin inhibitor, myoglobulin, ribonuclease, lysozyme, and cytochrome oxidase subunit IV; Bergers et al., 1993; Snel, de Kroon, \& Marsh, 1995), as well as in synthetic oligopeptides (Leenhouts, van den Wijngaard, de Kroon, \& de Kruijff, 1995). Physical adsorption processes, including electrostatic and/or hydrophobic interactions between proteins and lipids, are being proposed as the main driving forces in inducing protein conformational changes.

Herein, the formation of SF hydrogels using 1,2-dimyristoyl-snglycero-3-phospho-(1'-rac-glycerol) sodium salt (DMPG), a PG with 14-carbon chains, was demonstrated. Attenuated total reflection Fourier-transformed infrared (ATR-FTIR) with Fourier selfdeconvolution techniques and fluorescence spectroscopy were performed to investigate the mechanism of gelation. The microstructure, viscoelastic properties, biodegradability, and cytocompatibility with different cell types were thoroughly examined to evaluate the potential of the developed hydrogels for biomedical applications.

\section{2 | MATERIALS AND METHODS}

\section{1 | Materials}

Bombyx mori "Nangnoi Srisaket 1" Thai silk cocoons were obtained from Queen Sirikit Sericulture Center, Srisaket province, Thailand. DMPG and 1,2-dimyristoyl-sn-glycero-3-phosphocholine (DMPC) were purchased from Avanti Lipids Polar, USA. Cell culture medium and all other reagents were purchased from Thermo Fisher Scientific. All reagents were of analytical grade.

\subsection{SF solution preparation and its zeta potential determination}

SF solution was prepared using the method adapted from Kim, Park, Joo Kim, Wada, and Kaplan (2005). In brief, silk cocoons were boiled in $0.02 \mathrm{M} \mathrm{Na}_{2} \mathrm{CO}_{3}$ for 20 min, followed by their thoroughly washing with distilled water. The extracted silk fibre was then dissolved in 9.3 $\mathrm{M} \mathrm{LiBr}$ at $60^{\circ} \mathrm{C}$ for $4 \mathrm{hr}$. The silk solution was dialysed against distilled water using a dialysis tube (MWCO 12-16 kDa; Sekisui, Japan) for 48 hr. The final concentration was approximately $6 \%$, which was determined from dried solid weight.

Analysis of zeta potential of the SF solution was conducted using laser doppler electrophoresis in a Zetasizer Nano ZS equipment (Malvern Instruments) at $25^{\circ} \mathrm{C}$. 


\section{3 | Gelation time determination}

The SF solution was mixed with three different concentrations of DMPG (5, 10, and $15 \mathrm{mM}$; Figure 1a). The DMPG was first hydrated with distilled water and bath sonicated for $1 \mathrm{hr}$. Then, the SF solution was added, yielding $3 \% \mathrm{SF}$ in the final mixture. The $\mathrm{pH}$ of the mixtures was controlled using $10 \mathrm{mM}$ HEPES buffer ( $\mathrm{pH}$ 7.4). The gelation time was determined from the turbidity change, which was measured using optical density. These measurements were performed at $550 \mathrm{~nm}$ using a microplate reader (Synergy HT, Bio-Tek). Pure 3\% SF solution was used as control. The gelation time was determined from the time point at which the optical density reached a half maximum value. All experiments were conducted in triplicate.

The gelation time of DMPG-SF mixture in the presence of DMPC or $\mathrm{CaCl}_{2}$ was also evaluated. DMPG was mixed with DMPC (Figure 1 a) at different molar ratios (10:0, 7:3, 5:5, 3:7, and 0:10) before their mixing with SF. The gelation time was determined as described above. The effect of ionic salt addition in the gelation time of DMPG-SF mixtures was determined in the presence of $\mathrm{Ca}^{2+}$. Different concentrations of $\mathrm{CaCl}_{2}(0.1,0.5$, and $1 \mathrm{mM})$ were added to the DMPG-SF mixtures. White precipitates as well as a long gelation time (more than $240 \mathrm{~min}$ ) were noticed with amounts of $\mathrm{Ca}^{2+}$ greater than $1 \mathrm{mM}$.

\section{4 | Time course of the SF conformational changes by ATR-FTIR spectroscopy}

The conformational changes of SF during the gelation process were determined by FTIR (IRPrestige 21, Shimadzu) with an ATR ZnSe cell. The DMPG-SF mixture was dropcasted onto the cell and the spectrum was measured. The spectrum, from 4,000 to $800 \mathrm{~cm}^{-1}$, was obtained in an absorbance mode with $2.0 \mathrm{~cm}^{-1}$ resolution and 1 $\mathrm{cm}^{-1}$ interval.

Fourier self-deconvolution and curve fitting of the infrared spectra were performed according to Hu, Kaplan, and Cebe (2006) with slight modifications. The amide I region $\left(1,575-1,725 \mathrm{~cm}^{-1}\right)$ were deconvoluted using Omnic 8.0 software. The Voigt lineshape with a half bandwidth of $10 \mathrm{~cm}^{-1}$ and an enhancement factor of 3.0 was applied. The curve fitting of the deconvoluted spectrum was performed using Origin 9.0 software. The amount of beta sheet conformation was calculated from the sum of the percentage of area under the peaks in the 1,616 to $1,637 \mathrm{~cm}^{-1}$ and 1,696 to $1,703 \mathrm{~cm}^{-1}$ regions. The amount of tyrosine residue $\left(1,595-1,615 \mathrm{~cm}^{-1}\right)$, random coil $\left(1,638-1,655 \mathrm{~cm}^{-1}\right)$, alpha helix $\left(1,656-1,662 \mathrm{~cm}^{-1}\right)$, and beta turn $\left(1,663-1,696 \mathrm{~cm}^{-1}\right)$ structures were also calculated from the area under the defined peaks.
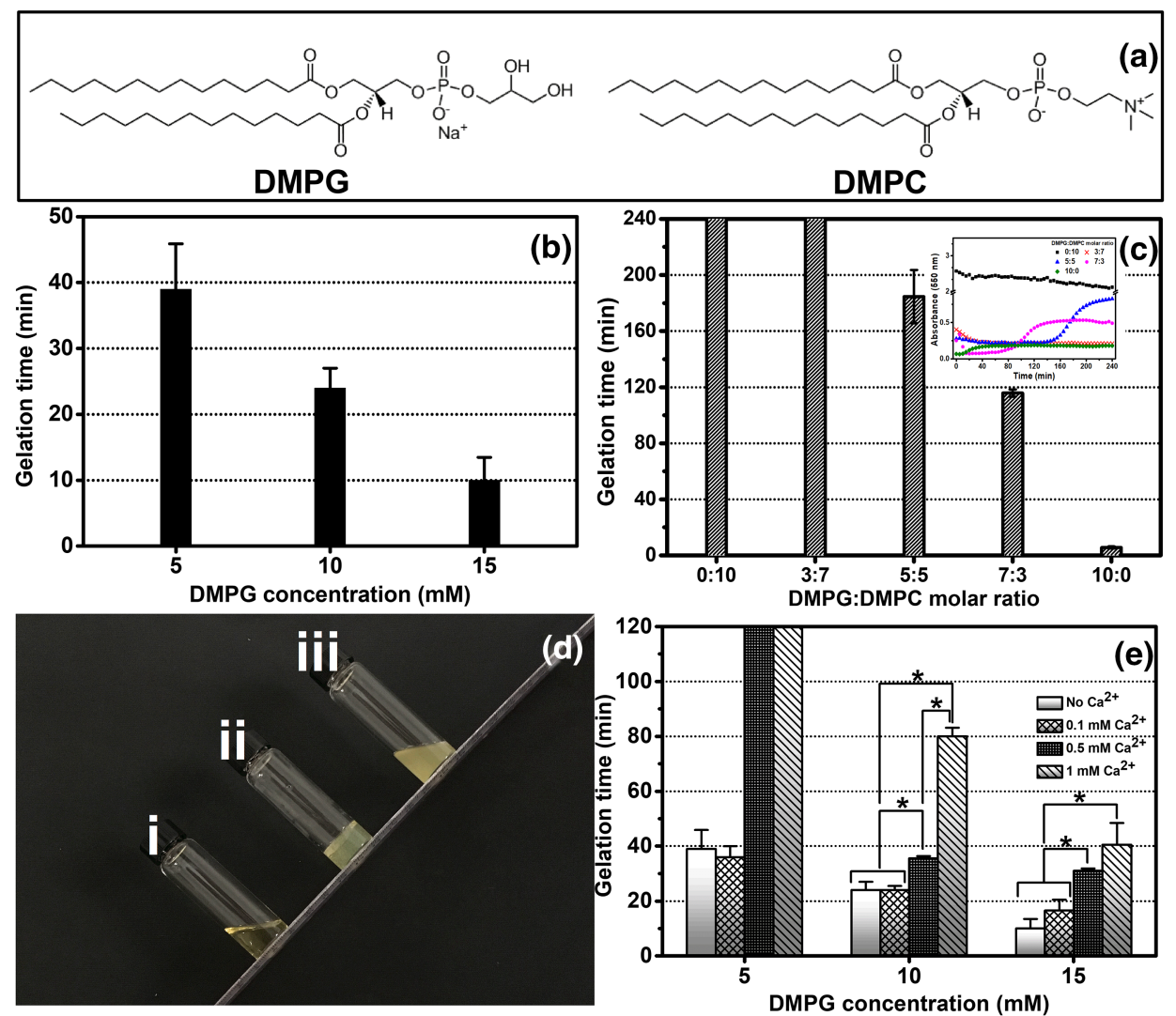

FIGURE 1 (a) Chemical structures of DMPG and DMPC. Gelation time of the DMPG-induced 3\% SF hydrogels in the presence of (b) different DMPG concentration, and (c) various DMPG:DMPC molar ratio. (d) Optical appearances after 1-hr incubation of the following mixtures (i) 3\% SF, (ii) $10 \mathrm{mM}$ DMPG-3\% SF, and (iii) $10 \mathrm{mM} \mathrm{DMPC-3 \%} \mathrm{SF.} \mathrm{(e)} \mathrm{Gelation} \mathrm{time} \mathrm{of} \mathrm{DMPG-3 \%} \mathrm{SF} \mathrm{mixtures} \mathrm{in} \mathrm{the} \mathrm{presence} \mathrm{of} \mathrm{various} \mathrm{Ca}{ }^{2+}$ and DMPG concentrations (for $5 \mathrm{mM} \mathrm{DMPG}$ with 0.5 and $1 \mathrm{mM} \mathrm{Ca}^{2+}$, the gel formation did not occur within 120 min). Asterisk $\left(^{*}\right)$ indicates statistically significant differences at $p \leq 0.05$ [Colour figure can be viewed at wileyonlinelibrary.com] 


\section{5 | Fluorescence spectroscopy}

Fluorescence measurements were performed using a spectrofluorometer (Viroskan flash, Thermo Fisher Scientific) to determine the folding of the SF protein during gelation.

For quenching experiments, 5, 10, and $15 \mathrm{mM} \mathrm{DMPG}$ and 3\% SF were mixed with acrylamide in concentrations ranging from 0 to 0.4 $\mathrm{M}$. The mixtures were incubated overnight at $37^{\circ} \mathrm{C}$ to allow gel formation. Pure SF hydrogels with different concentrations of acrylamide were prepared by their incubation under vapour-saturated atmosphere at $37^{\circ} \mathrm{C}$ until gelation ( 7 days). Fluorescence emission spectra between 300 and $450 \mathrm{~nm}$ were collected using an excitation wavelength at $295 \mathrm{~nm}$, corresponding to the characteristic absorption of tryptophan. The analyses of the obtained data were performed using the Stern-Volmer equation:

$$
\mathrm{F}_{0} / \mathrm{F}=1+\mathrm{k}_{\mathrm{sv}}[\mathrm{Q}]
$$

where $F_{0}$ and $F$ are the maximum emission intensities in the absence and presence of acrylamide, respectively. [Q] is the concentration of quencher, and $k_{s v}$ is the Stern-Volmer constant obtained from the slope of the plot of $F_{0} / F$ versus [Q] (Lakowicz, 1999; X. Zhang \& Keiderling, 2006).

\subsection{Micromorphological structures of the hydrogels}

The 5, 10, and $15 \mathrm{mM}$ DMPG-3\% SF hydrogels were formed in a $37^{\circ}$ $\mathrm{C}$ chamber for $1 \mathrm{hr}$ before overnight frozen at $-80^{\circ} \mathrm{C}$ and freeze dried (CryoDos 80, Telstar); 3\% SF hydrogel was prepared accordingly after its gelation. The lyophilized samples were then cut and sputter coated with platinum. The morphology was observed using a scanning electron microscope (SEM; JSM-6010LV, Jeol). Pore size of the hydrogels were determined using the ImageJ software $(n=5)$.

\subsection{Viscoelastic properties of the hydrogels}

The modulus of the DMPG-SF hydrogels was determined using a rheometer (Kinexus Pro+, Malvern Instrument) in an oscillatory mode. After mixing the SF with DMPG, the mixture was transferred to a parallel plate with 1-mm gap. First, the time sweep was performed with a constant strain $(0.5 \%)$ and frequency $(1 \mathrm{~Hz})$, for at least $1 \mathrm{hr}$ to ensure the complete hydrogel formation. When the constant modulus was reached, the frequency sweep $(0.1-100 \mathrm{~Hz}$, $0.5 \%$ strain) was applied, followed by the strain sweep (0.1-100\%) under a constant frequency at $1 \mathrm{~Hz}$. All experiments were performed at $37^{\circ} \mathrm{C}$.

\section{8 | In vitro degradation of the hydrogels}

In vitro degradation of the hydrogels was performed by their incubation with one unit per millilitre of protease XIV in $10 \mathrm{mM}$ HEPES $(\mathrm{pH} 7.4)$ with $0.01 \%$ sodium azide. The protease XIV was selected due to its efficiency of SF digestion (Li, Ogiso, \& Minoura, 2003). The incubation temperature was $37^{\circ} \mathrm{C}$, and the media were changed twice a week. The weight of the hydrogels was measured at designated time points (Day 0, 1, 3, 7, 14, and 21), and the weight loss percentage was calculated $(n=4)$.

\subsection{Cell encapsulation and culture in DMPG-SF hydrogels}

L929, NIH/3T3, and SaOS-2 were cultured in Dulbecco's Modified Eagle's Medium, 10\% fetal bovine serum (FBS) and 1\% antibiotic/antimycotic solution. Minimum Essential Medium Eaglealpha modification was used instead of Dulbecco's Modified Eagle's Medium for culturing CaSki. All cell lines were incubated at $37^{\circ} \mathrm{C}$ in a humidified $5 \% \mathrm{CO}_{2}$ chamber. The culture media were changed every 2-3 days, and the subculture was performed when cells reached approximately $80 \%$ confluency.

For cell encapsulation, the SF solution was steam-sterilized at $121^{\circ} \mathrm{C}$ for $30 \mathrm{~min}$, and DMPG was irradiated by ultraviolet light for $30 \mathrm{~min}$. Then, the lipid film was hydrated with $5 \%$ dextrose sterile solution (to control the physiological osmolarity; Carvalho, Gasperini, Ribeiro, Marques, \& Reis, 2018). Afterwards, the suspension was added to a mixture of SF and cells to obtain a final concentration of $3 \%$ SF and a cell density of $1 \times 10^{6}$ cells per millimetre. Cellsuspended DMPG-SF mixtures were transferred to a silicone mould and incubated for $1 \mathrm{hr}$ in a $\mathrm{CO}_{2}$ incubator to allow gel formation. Cell-loaded hydrogels were punched to disc shape with 5-mm diameter and 2-mm thickness (smaller than those referred in Data S1, to ensure an adequate nutrients and wastes diffusion) and transferred to a new 24-well plate. Then, 1-ml culture medium was added. All plates were incubated at $37^{\circ} \mathrm{C}$ with $5 \% \mathrm{CO}_{2}$, and the media were changed every other day.

\subsection{0 | Cell viability and proliferation}

The indirect cytotoxicity of DMPG-SF hydrogels was assessed as described in Data S1. Before encapsulating cells into the developed biomaterials, the cell lines were cultured on 2D tissue culture plates to analyse their normal proliferation profile (Data S2).

The number of viable cells encapsulated in the DMPG-SF hydrogels were evaluated at each time point (Day 0, 1, 3, 7, 14, and 21) by a colorimetric 3-(4,5-dimethylthiazol-2-yl)-2,5-diphenyltetrazolium bromide (MTT) assay, following the instructions of the manufacturer. Briefly, the hydrogel samples were first minced and incubated with the MTT solution at $37^{\circ} \mathrm{C}$ for $3 \mathrm{hr}$. Afterwards, DMSO was added to extract the insoluble formazan product (developed from the reduction of MTT by an enzyme present in viable cells). The absorbance at $570 \mathrm{~nm}$ was measured, and the values obtained from acellular hydrogels were used to correct the values of samples. The number of cells was calculated using a standard curve.

Plots of cell number versus culture time in log scale were used to determine specific growth rate $(\mu)$ from the slope of exponential 
growth period. Population doubling time (PDT) was calculated using the following equation:

$$
\mathrm{PDT}=\frac{\ln 2}{\mu} .
$$

\subsection{1 | Cell viability and morphology}

Cell viability was evaluated by live and dead cell staining. At each time point (1, 3, 7, 14, and 21 days), the cell-loaded hydrogels were washed with PBS and horizontally cut into thin slices (approximately 100 to $200 \mu \mathrm{m}$ thickness). The hydrogels were then incubated with Calcein $\mathrm{AM}$ and propidium iodide for $30 \mathrm{~min}$ at $37^{\circ} \mathrm{C}$. Images of the fluorescent-labelled cells in the hydrogels were obtained using a fluorescence microscope (Eclipse $\mathrm{C} 1$, Nikon Instruments).

DAPI and phalloidin cell staining were used to assess the morphology of the encapsulated cells. For that, the cell-loaded hydrogels were washed and fixed with 10\% neutral-buffered formalin for $1 \mathrm{hr}$. After this period of time, the samples were incubated with phalloidin-FITC and DAPI for $1 \mathrm{hr}$. Cells morphology were analysed using the fluorescence microscope previously referred, and images at various depths were acquired.

\subsection{2 | Statistical analysis}

Statistical analysis was performed using IBM SPSS Statistics (Version 22). Data were analysed by one-way analysis of variance and Bonferroni post hoc test. Differences were considered statistically significant when $p \leq 0.05$.

\section{3 | RESULTS}

\section{1 | Gelation time of DMPG-SF mixtures}

The gelation time of DMPG-SF mixtures determined from the time point at which the optical density reaches the half maximum value is shown in Figure 1b. Mixtures of 5, 10, and $15 \mathrm{mM}$ DMPG and 3\% SF presented a gelation time of $39 \pm 6.9,24 \pm 3.0$, and $10 \pm 3.5 \mathrm{~min}$, respectively. These results are much lower than those obtained for a $3 \%$ SF solution (approximately 7 days at $37^{\circ} \mathrm{C}$ ). Therefore, DMPG can remarkably induce a fast gelation of SF. Moreover, the increasing of DMPG concentration significantly decreased the time required to obtain SF hydrogels.

To confirm the influence of lipids with different head groups on SF gelation, DMPC (Figure 1a), a zwitterionic phospholipid with a similar hydrophobic tail of DMPG (Figure 1a), was used. DMPC was mixed with DMPG at different molar ratios (Figure 1c). With $10 \mathrm{mM}$ DMPC or a mixture of DMPG:DMPC at 3:7 molar ratio, the hydrogels were not formed within the experimental time considered (240 min). Higher ratios of DMPG to DMPC (5:5 and 7:3) significantly decreased the gelation time (185 \pm 19 and $116 \pm 3 \mathrm{~min}$, respectively). The inset in Figure 1c shows the absorbance of the lipids-SF mixtures at $550 \mathrm{~nm}$ over time. The highest absorbance intensities were obtained for the mixture of DMPC and SF, due to its opacity. However, the gelation of this mixture did not occur, which was also confirmed by visual observation after finishing the measurements (Figure 1d).

The effect of charge on the gelation time of DMPG-SF mixtures was analysed by addition of an ionic salt, namely, $\mathrm{CaCl}_{2}$ at concentrations ranging from 0.1 to $1 \mathrm{mM}$. The results are presented in Figure $1 \mathrm{e}$. For a small amount of $\mathrm{Ca}^{2+}(0.1 \mathrm{mM})$, there were no statistically significant differences. However, the increase of $\mathrm{Ca}^{2+}$ concentration significantly extended the gelation time, excepting the $\mathrm{Ca}^{2+}$ concentrations of 0.5 and $1 \mathrm{mM}$ in presence of the $15 \mathrm{mM}$ DMPG.

\section{2 | SF conformational transitions during the gelation process}

Due to the long gelation time of the control (pure SF), FTIR measurements were performed with freeze-dried samples obtained at each time point up to 14 days and the protein secondary structures were analysed. SF solution turned gel at approximately 7 days, which is in accordance to an increase of beta sheet structure and a reduction of the amount of random coil and alpha helix conformers (Figure 2a).

The time-lapse ATR-FTIR measurements were performed to determine the conformational transitions of SF during the gelation process in the different DMPG-SF mixtures. In the amide I region (1,725$1,575 \mathrm{~cm}^{-1}$ ), the peak shifts towards approximately $1,625 \mathrm{~cm}^{-1}$ indicate the formation of beta sheet (Figure S1A-C). The peak deconvolution followed by the curve fitting was performed to quantify the SF conformational changes during the gelation process (Figure S1D), and the results were presented in Figure $2 b-d$. Similar to the control, the percentage of beta sheet increased upon the gelation time of the different mixtures. After that, the amount of beta sheet was almost constant until the end of the measurements. Conversely, the percentage of random coil, beta turn, and alpha helix conformations decreased during the gelation process.

\section{3 | Micro-environment changes of SF protein}

Fluorescence spectroscopy allows the investigation of the hydrophilic-hydrophobic interactions of proteins by tracing the localization of the tryptophan residues. Approximately $0.2-0.5 \%$ of tryptophan is present (Kaewprasit, Promboon, Kanokpanont, \& Damrongsakkul, 2014) and dispersedly located in the linkers between crystalline regions of the SF chains (Zhou et al., 2001). This enables a study of the micro-environment changes of SF during structural transitions. The emission spectra acquired every 5 min of 5 mM DMPG-3\% SF in a range from 300 to $450 \mathrm{~nm}$ are shown in Figure 2e. The increasing of the emission intensities of tryptophan (inset in Figure 2e) together with a blue shift from 324 to $314 \mathrm{~nm}$ indicated the insertion of tryptophan into a hydrophobic pocket, which is related with a reduction of the quenching effect provided by the hydrophilic environment (Lakowicz, 1999).

The fluorescence quenching technique is used to determine lipidprotein interactions. The assessment of the shielding of the 

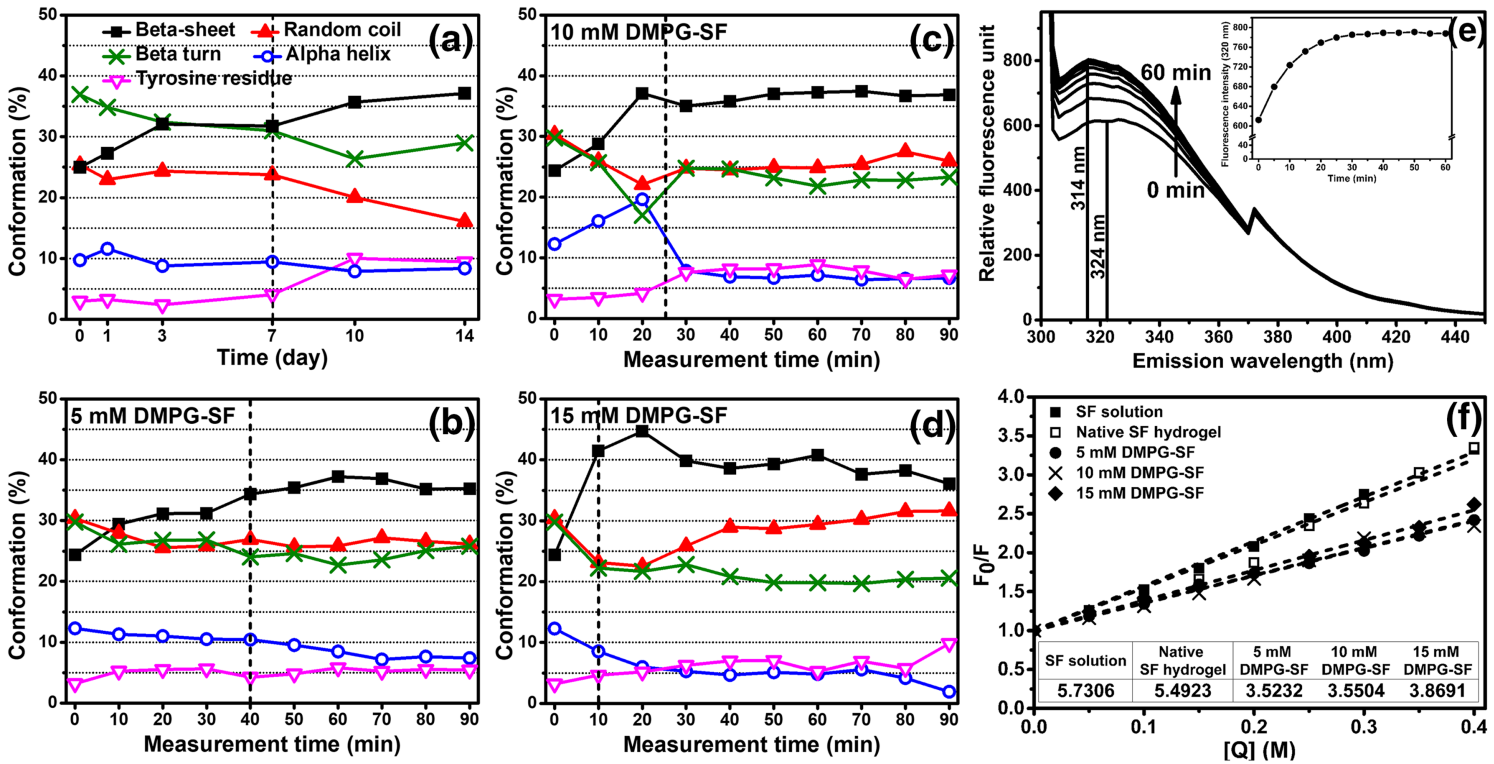

FIGURE 2 Conformation percentage changes during the gelation of (a) lyophilized 3\% SF and (b-d) 5, 10 and 15 mM DMPG-3\% SF mixtures. (e) Fluorescence emission spectra (excitation/emission wavelengths of $290 \mathrm{~nm} / 300-450 \mathrm{~nm}$ ) of the structural transition of $5 \mathrm{mM}$ DMPG-3\% SF. An inset shows the increase of emission intensity $(320 \mathrm{~nm}$ ) during the period of incubation. (f) Stern-Volmer plot from acrylamide quenching experiments of SF solutions and hydrogels in the presence or absence of DMPG. Inset table presents the Stern-Volmer constants obtained from the linear fit according to the Stern-Volmer equation [Colour figure can be viewed at wileyonlinelibrary.com]

tryptophan fluorescence from hydrophilic acrylamide quenchers was performed. Figure $2 f$ shows the Stern-Volmer plot obtained from the acrylamide quenching experiments of DMPG-induced SF hydrogels, as well as their comparison with those acquired with SF solutions and pure SF hydrogels. A lower Stern-Volmer constant is related to a higher difficulty in the quencher accessing to tryptophan (Lakowicz, 1999; X. Zhang \& Keiderling, 2006). All DMPG-SF samples presented Stern-Volmer constants lower than those of SF solutions and pure SF hydrogels (inset table of Figure 2f). Presumably, the tryptophan was not accessible to acrylamide, due to its insertion in the hydrophobic part of DMPG molecules.

\section{4 | Morphology and pore size of the lyophilized hydrogels}

SEM micrographs of lyophilized SF and DMPG-SF hydrogels are shown in Figure $3 a-d$. The cross-sectional images show structures with average pore sizes of $4.89 \pm 1.28,52.8 \pm 11.3,50.4 \pm 12.4$, and $59.7 \pm 14.0 \mu \mathrm{m}$ for $3 \%$ SF hydrogel and 5, 10, and $15 \mathrm{mM}$ DMPG$3 \%$ SF hydrogels, respectively (Figure 3e). A significantly bigger pore size was noticed for DMPG-induced SF hydrogels when compared with the SF hydrogels. There were no significant differences between the pore sizes of 5 and 10 mM DMPG-SF hydrogels. However, for 15
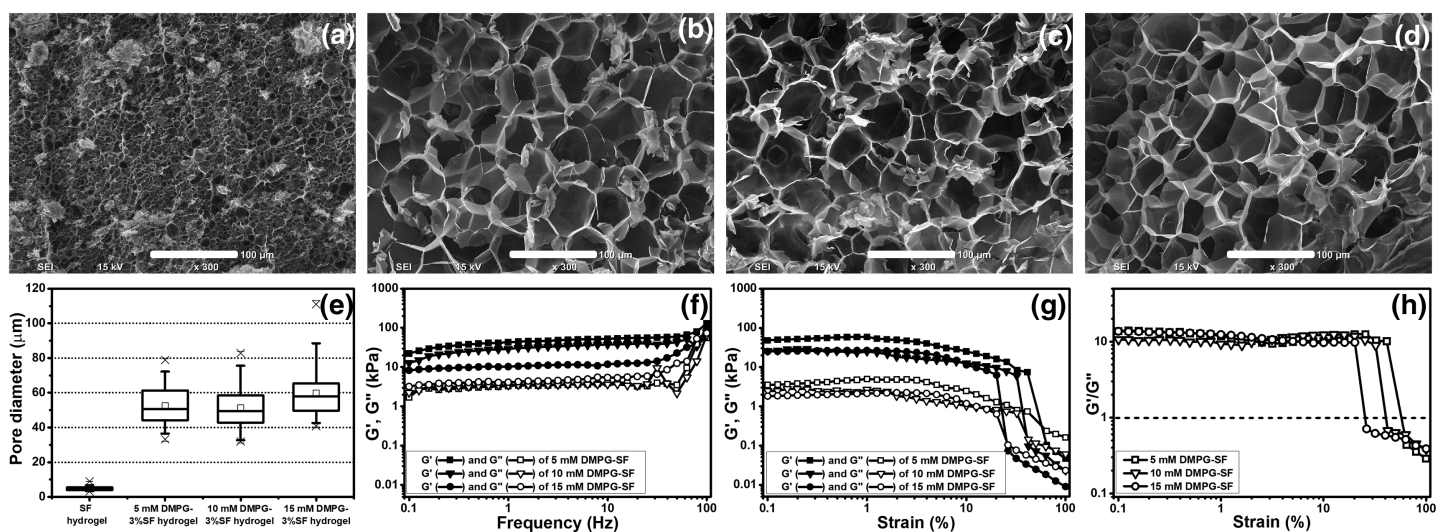

FIGURE 3 SEM micrographs of the cross-sectional (a) 3\% SF lyophilized hydrogel and (b) 5, (c) 10, and (d) 15 mM DMPG-3\% SF lyophilized hydrogels. Scale bars $=100 \mu \mathrm{m}$. (e) Pore size analysis from SEM images of SF and DMPG-SF hydrogels. (f) Frequency sweep experiments (0.1$100 \mathrm{~Hz}$ ) with a fixed strain (0.5\%) and (g) strain sweep experiments $(0.1-100 \%)$ with a constant frequency $(1 \mathrm{~Hz})$, at $37^{\circ} \mathrm{C}$. (h) Plot of $\mathrm{G}^{\prime} / \mathrm{G}^{\prime \prime}$ of the different mixtures versus shear strain (0.1-100\%). The dash line indicates $G^{\prime} / G^{\prime \prime}=1$ 
mM DMPG-SF hydrogels, the pore sizes were significantly higher, comparing with other DMPG-SF hydrogels.

\section{5 | Viscoelastic properties of the DMPG-SF hydrogels}

The elastic $\left(G^{\prime}\right)$ and viscous $\left(G^{\prime \prime}\right)$ moduli from frequency sweep and strain sweep experiments were collected after the constant modulus was reached in time sweep experiment (Figure S2), and the results are shown in Figure 3f,g. With an increment of frequency (0.1-100 $\mathrm{Hz}$ ), the $\mathrm{G}^{\prime}$ and $\mathrm{G}^{\prime \prime}$ values of the hydrogels slightly increased until approximately $20 \mathrm{~Hz}$. After this point, their increase was more pronounced (Figure 3f). The $G^{\prime}$ values of the hydrogels decreased with the increase of DMPG concentration, which is in an agreement with the results obtained from strain sweep experiments (Figure 3e). The $G^{\prime}$ and $G^{\prime \prime}$ values presented almost the same behaviour over a range of strain from $0.1 \%$ to $40 \%$, before they lower sharply for higher shear strain values. From the $\mathrm{G}^{\prime} / \mathrm{G}^{\prime \prime}$ versus shear strain plot (Figure $3 \mathrm{~h}$ ), the $\mathrm{G}^{\prime \prime}$ is higher than $\mathrm{G}^{\prime}\left(\mathrm{G}^{\prime} / \mathrm{G}^{\prime \prime} \leq 1\right)$ after $41.3 \%, 32.3 \%$, and $20.2 \%$ shear strain for 5, 10, and 15-mM DMPG and 3\% SF hydrogels, respectively. This indicates that the hydrogels lose their mechanical stability when a high shear strain is applied. Furthermore, the hydrogels containing higher DMPG amounts showed a lower mechanical stability, since that their viscous modulus predominates at lower shear strain values.

\section{6 | Degradation profile}

From Figure 4, it is possible to observe significant differences between 5 and $15 \mathrm{mM}$ DMPG-3\% SF hydrogels at 14 and 21 days, indicating that the presence of a higher DMPG amount resulted in a lower weight loss in the presence of the protease. After 21 days of the experiment, the $3 \%$ SF and DMPG-SF hydrogels degraded approximately $15-30 \%$ in the enzyme solution. The weight of the DMPGSF samples of the control group (in HEPES buffer) reduced around $5 \%$ of their initial weight. Conversely, the weight of pure SF hydrogel slightly increased $(\sim 2 \%)$, indicating the swelling properties of regenerated SF hydrogels.

\section{7 | Proliferation of the encapsulated cells}

Before performing cell encapsulation experiments, the cytocompatibility of the DMPG-induced SF hydrogels was evaluated using indirect cytotoxicity testing in accordance with ISO 109931:2009 (ISO, 2009). The results indicated that all DMPG-SF samples were cytocompatible and did not induce a significant alteration on the morphology of L929 cells (Figures S3 and S4).

Encapsulated L929 and NIH/3T3 fibroblasts showed normal proliferation patterns (Figure $5 \mathrm{a}, \mathrm{b}$ ) with a delayed lag phase ( 3 and 7 days for $\mathrm{L} 929$ and $\mathrm{NIH} / 3 \mathrm{~T} 3$, respectively) and an extended exponential growth period (3-14 days and 7-21 days for L929 and NIH/3T3, respectively), comparing with the values obtained from $2 \mathrm{D}$ culture (Figure S5). The PDT values of L929 and NIH/3T3 cultured in the $3 \mathrm{D}$ hydrogel matrices were significantly higher than in the $2 \mathrm{D}$ culture

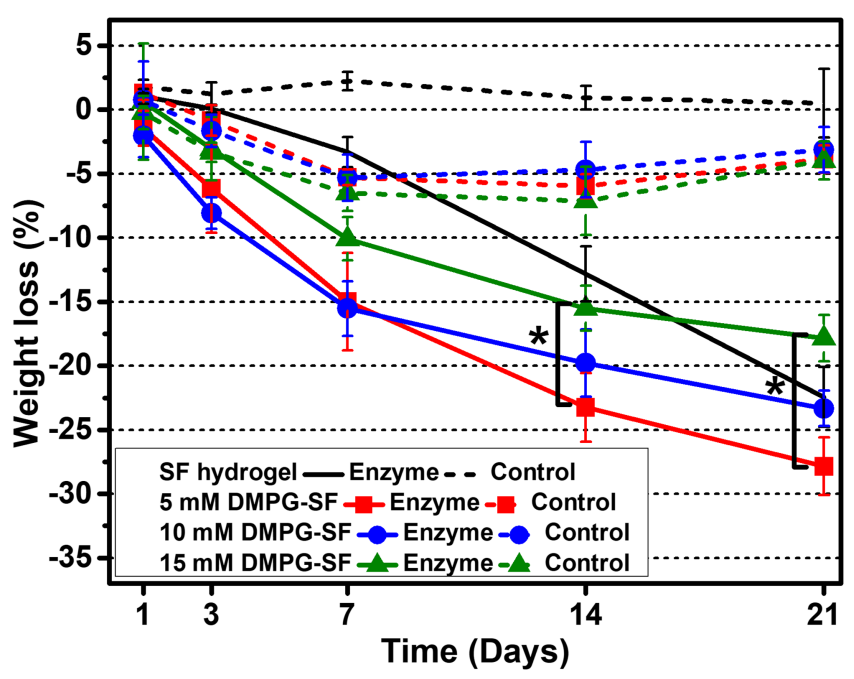

FIGURE 4 Degradation profiles of the $3 \%$ SF and DMPG-SF hydrogels in the control media (HEPES buffer, $\mathrm{pH} 7.4$ ) and in the presence of an enzyme (HEPES buffer containing protease XIV, 1 unit per millilitre) at $37^{\circ} \mathrm{C}$ for 21 days. Asterisk $\left(^{*}\right)$ indicates statistically significant differences at $p \leq 0.05$ [Colour figure can be viewed at wileyonlinelibrary.com]

(Table 1). A distinct proliferation profile was observed for encapsulated SaOS-2. The cell numbers after 7 days of culture remained approximately the same until the end of experiment (Figure 5c). Therefore, the $\mu$ and PDT could not be calculated for this cell type. For CaSki, their growth was lower with the increasing of the DMPG amount used to induce SF gelation, mainly at Day 21 (Figure $5 \mathrm{~d}$ ). As a result, the PDT values of encapsulated CaSki increased with the DMPG concentration.

\section{8 | Cell viability and morphology}

Figure 6a-e shows live (green) and dead (red) L929 cells encapsulated in $10 \mathrm{mM}$ DMPG-3\% SF hydrogels at different time points (Day 1, 3, 7, 14, and 21). Almost all the cells distributed in the hydrogel matrices remained viable, indicating the value of this approach for cell encapsulation.

The morphology of cells loaded in DMPG-SF hydrogels was investigated using DAPI and phalloidin-FITC staining, allowing the identification of the nucleus and cytoplasm of the cells, respectively (Figure 6f). The encapsulated cells presented a round shape, with no noticeable changes over 21 days of culture. Additionally, no statistically significant differences were obtained between the SF hydrogels with different DMPG concentrations in terms of the biological parameters evaluated.

\section{4 | DISCUSSION}

The regenerated SF solutions usually turn gel through a self-assembly process, in which chain rearrangement and hydrogen bonding occur, leading to the transition of random coil to the highly stable beta sheet 

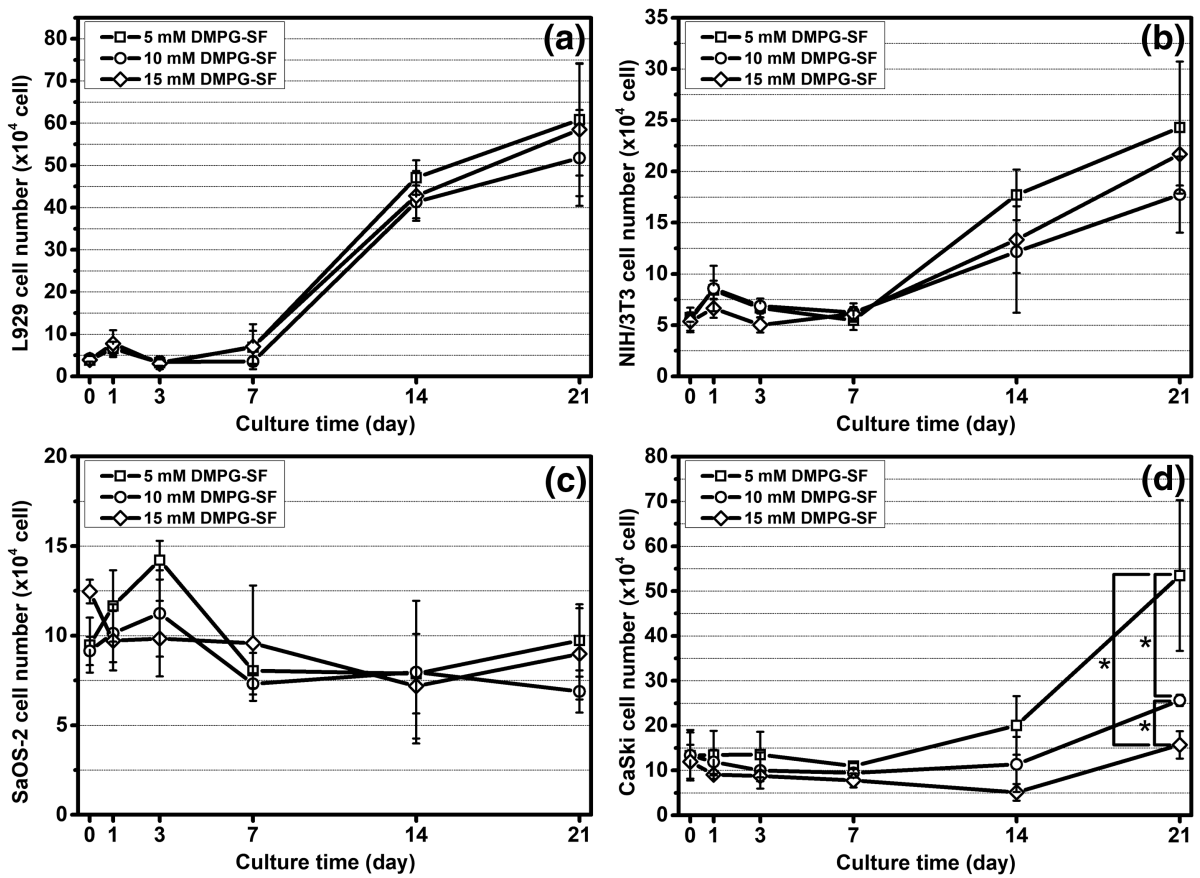

FIGURE 5 Proliferation profile of encapsulated cells, namely, (a) L929, (b) NIH/3T3, (c) SaOS-2, and (d) CaSki in 5, 10, and 15 mM DMPG-3\% SF hydrogels determined by the MTT assay. Asterisk $\left({ }^{*}\right)$ indicates statistical differences at $p \leq 0.05$

TABLE 1 Population doubling time (day) of encapsulated cells in DMPG-SF hydrogels or cultured in 2D tissue culture plates (TCPs)

\begin{tabular}{llccl} 
Cells & $\begin{array}{l}5 \mathrm{mM} \\
\text { DMPG-SF }\end{array}$ & $\begin{array}{l}10 \mathrm{mM} \\
\text { DMPG-SF }\end{array}$ & $\begin{array}{l}15 \mathrm{mM} \\
\text { DMPG-SF }\end{array}$ & TCPs \\
L929 & 2.82 & 2.88 & 2.85 & 0.68 \\
NIH/3T3 & 8.12 & 10.01 & 8.11 & 0.93 \\
SaOS-2 & N/A & N/A & N/A & 1.32 \\
CaSki & 6.12 & 9.73 & 13.80 & 1.01 \\
\hline
\end{tabular}

(Matsumoto et al., 2006). However, this process takes a very long time, and consequently, their use as a 3D cell carrier is not feasible. Several strategies have been employed to accelerate the structural transition of SF. Different amphipathic molecules, such as surfactants and lipids, are known to interfere with the arrangement of SF chains and to enhance the formation of beta sheet structures via electrostatic and hydrophobic interactions (Dubey et al., 2015; Wu et al., 2012; F. Zhang et al., 2015).

PGs, amphipathic phospholipids with hydrophobic alkyl chains and glycerol head groups, can stimulate conformational changes in several proteins (Bañuelos \& Muga, 1996; Bergers et al., 1993; Leenhouts et al., 1995; Snel et al., 1995; X. Zhang \& Keiderling, 2006). Furthermore, PGs are biologically occurring phospholipids (Buckland \& Wilton, 2000) and are widely used in liposomes preparation (Nogueira, Gomes, Preto, \& Cavaco-Paulo, 2015), being their biocompatibility already demonstrated. In this study, the mixing of DMPG with SF solutions led to hydrogels formation within approximately 10 to 40 min depending on DMPG concentrations (Figure $1 \mathrm{~b}$ ). These results were corroborated by the data obtained in the time course of SF conformational change measurements. Indeed, these analyses demonstrated that the beta sheet percentage increases until reaching a plateau corresponding to the hydrogel formation (Figure $2 b-d$ ). Therefore, DMPG can stimulate and enhance structural transitions, yielding the beta sheet structure that is responsible for the SF hydrogel formation.

The assessment of the effect of the lipid charge on the SF gelation showed that DMPC or its mixture with DMPG is not as effective as pure DMPG in reducing the SF gelation time (Figure 1c). In addition, the presence of $\mathrm{Ca}^{2+}$ in the DMPG-SF mixtures negatively influenced the hydrogel formation. The amount of this divalent cation as low as 1:30 ( $\mathrm{Ca}^{2+}$ :DMPG molar ratio) significantly increased the gelation time (Figure 1e). These results indicate that the negative charge of the DMPG polar head is crucial to induce the structural changes in SF polypeptide chains. As SF solutions possesses a negative charge $(-7.08 \mathrm{mV}$ at $\mathrm{pH} 7.4)$, which is in an agreement with published results (Wu et al., 2012), the electrical repulsion between SF chains and the negatively charged DMPG may occur. Additionally, DMPG might interact with cationic residues that are inhomogeneously distributed in the SF chain (Zhou et al., 2001). These electrostatic interactions can lead to an extension or unfolding of SF chains before chain rearrangement into beta sheet aggregates. The hydrophobic interactions between the phospholipids and SF chains were confirmed by fluorescence quenching experiments (Figures 2e,f). A lower Stern-Volmer constant of DMPG-SF samples compared with pure SF hydrogel indicated that tryptophan residues, dispersedly located in SF chains, were more inaccessible to the acrylamide quencher. Probably, a hydrophobic interaction with DMPG could shield tryptophan from the hydrophilic environment. Therefore, we propose that the electrostatic interactions provided by the anionic DMPG are required for SF chain extension and unfolding from random chain assembly in SF solution. The hydrophobic domain of SF will undergo structural rearrangements through 

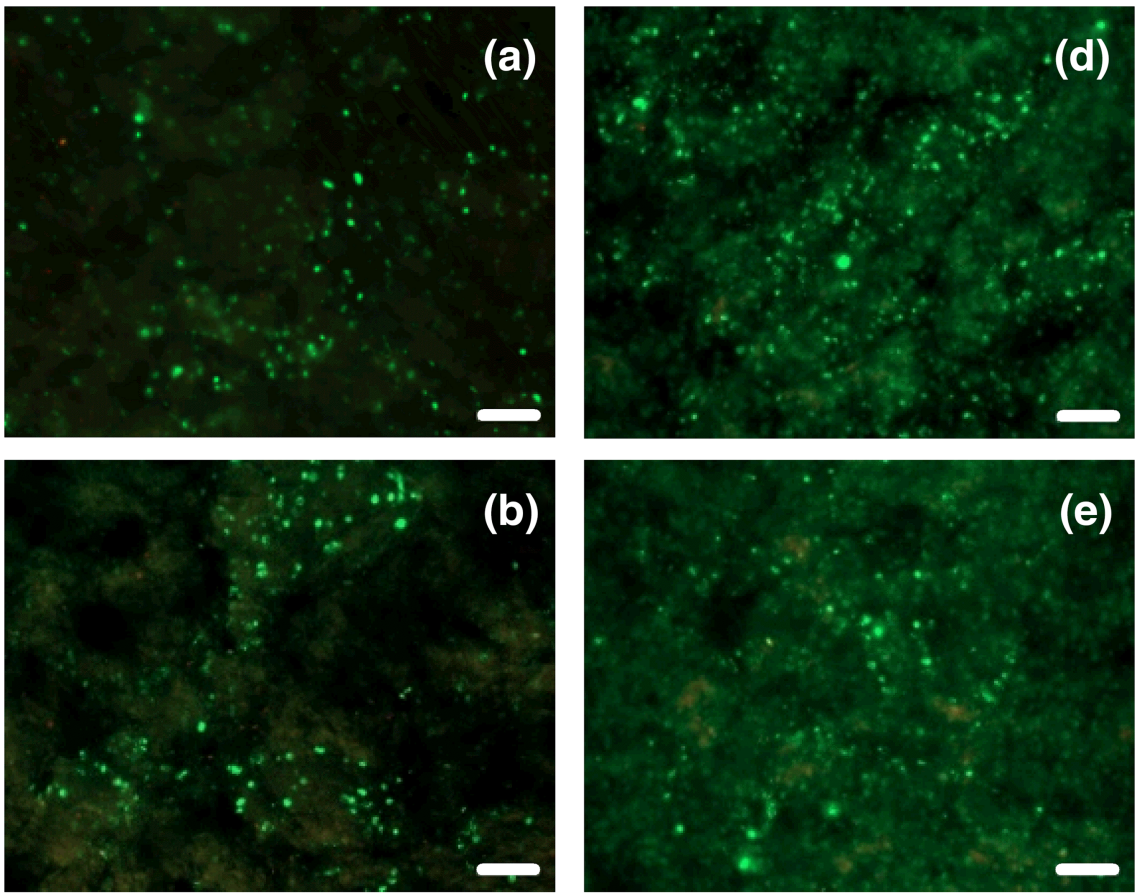

FIGURE 6 Live/dead staining of L929 encapsulated in $10 \mathrm{mM}$ DMPG-3\% SF hydrogels at each time point (Days 1 [a], 3 [b], 7 [c], 14 [d], and 21 [e]). Green and red dots indicate live and dead cells, respectively. Scale bar $=100 \mu \mathrm{m}$. (f) Morphology of encapsulated L929 cells after 21 days of culture. Green and blue fluorescence indicate cell cytoplasm and nucleus, respectively. Scale bar $=50 \mu \mathrm{m}$ [Colour figure can be viewed at wileyonlinelibrary.com]
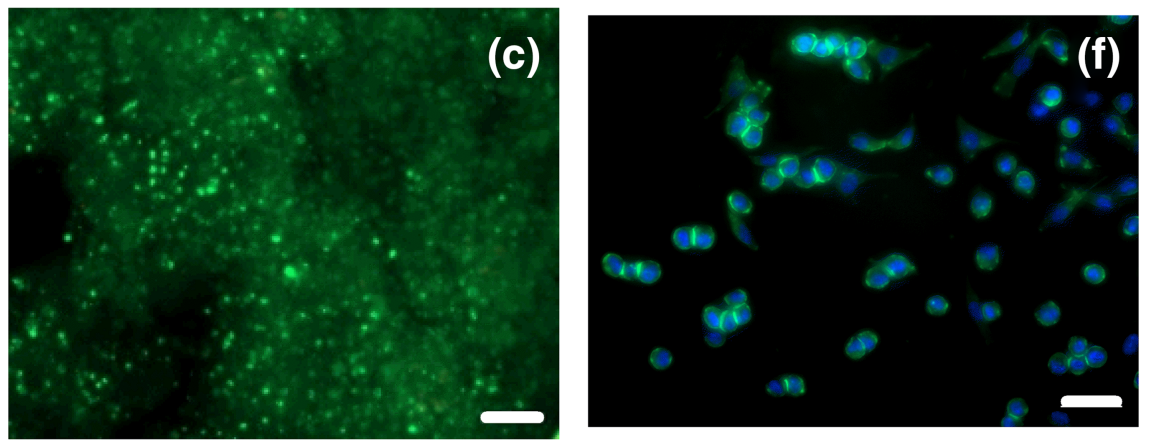

hydrophobic interactions with DMPG to form a stable beta sheet conformation. An increase of DMPG concentration resulted in higher number of negative charges and of hydrophobic domains, leading to a faster structural transition and lower gel formation time.

The assessment of the in vitro degradation (Figure 4) showed that the samples with the highest DMPG content lost the lowest mass. Dissolution of DMPG during incubation was presumed, due to the weight loss of hydrogels observed in the control buffer. The weight of SF hydrogel without DMPG slightly increased ( $2 \%)$, whereas the weight of DMPG-SF samples decreased approximately $5 \%$. The viscoelastic properties determination showed that the storage modulus of the samples slightly decreased with an increasing of the DMPG amount (Figure 3f,g). Furthermore, the $15 \mathrm{mM}$ DMPG-SF hydrogels reached the failure point at the lowest strain value when compared with the other formulations (Figure 3h). Yin et al. (2017) proposed that not only the beta sheet structure is responsible for the viscoelasticity of SF hydrogels, but also the weak and reversible hydrogen bonds. Certainly, hydrogen bonds can be formed between the polar head of DMPG (Garidel, Blume, \& Hübner, 2000) and SF. This may reduce the hydrogen bonding between the protein and water as previously discussed (Jones, 1992). Thus, the higher amount of DMPG might lead to a decrease of the SF hydrogen bonds, which will affect the viscoelastic properties of SF hydrogels.

The gelation times from 10 to $40 \mathrm{~min}$ are appropriate for cell encapsulation, allowing suitable time for mixing cells in the solution and turning to gel while cells are homogeneously suspended. SEM images of the lyophilized hydrogels showed a presence of a porous microstructure. This property together with adequate mechanical properties and slow degradability of the hydrogels are essential for cell encapsulation. Additionally, they can mimic the extracellular matrix, providing a mechanical support for cell viability and function and allowing nutrients, gas, and waste diffusion, which directly influence cells survival. Table 2 summarizes different in situ SF hydrogels that have been used for cell culture. Most of the cell encapsulation systems with gelation times less than $1 \mathrm{hr}$ show that cells are finely distributed over hydrogel matrices. Moreover, the encapsulated cells were able to survive and proliferate over 2 to 3 weeks. In this work, the results obtained from biological assays also revealed that DMPG-induced SF hydrogels are cytocompatible (Figures S3 and 5). Cells were homogeneously distributed in the hydrogel matrix and alive during 21 days of culture (Figure 6). Interestingly, different cell lines presented different cell growth behaviours. Fibroblastic cell lines, including L929 and 
TABLE 2 Cytocompatibility assessment of in situ SF hydrogels for cell encapsulation prepared by different methods

\begin{tabular}{|c|c|c|c|c|c|c|c|}
\hline \multirow[b]{2}{*}{$\begin{array}{l}\text { SF gelation induced } \\
\text { methods }\end{array}$} & \multicolumn{2}{|c|}{ Type of method } & \multirow[b]{2}{*}{$\begin{array}{l}\text { SF } \\
\text { concentration }\end{array}$} & \multirow[b]{2}{*}{$\begin{array}{l}\text { Gelation } \\
\text { time }\end{array}$} & \multirow[b]{2}{*}{ Cells } & \multirow{2}{*}{$\begin{array}{l}\text { Culture } \\
\text { period } \\
\text { (days) }\end{array}$} & \multirow[b]{2}{*}{ Ref. } \\
\hline & $\begin{array}{l}\text { Physical } \\
\text { intervention }\end{array}$ & $\begin{array}{l}\text { Chemical } \\
\text { additive }\end{array}$ & & & & & \\
\hline \multirow{2}{*}{ Sonication } & \multirow{2}{*}{$\checkmark$} & & $2 \%$ & $2 \mathrm{hr}$ & $\mathrm{hMSC}^{\mathrm{a}}$ & 28 & Calabrese et al. (2017) \\
\hline & & & $1 \%$ & $1 \mathrm{hr}$ & $\mathrm{hNSC} \mathrm{C}^{\mathrm{b}}$ & 7 & Sun et al. (2017) \\
\hline Vortexing & $\checkmark$ & & $1.2 \%$ & $2 \mathrm{hr}$ & $\begin{array}{l}\text { Mouse islet and } \\
\text { BMSC }^{c}\end{array}$ & 42 & Hamilton et al. (2017) \\
\hline \multirow{2}{*}{$\begin{array}{l}\text { Horseradish } \\
\text { peroxidase } / \mathrm{H}_{2} \mathrm{O}_{2}\end{array}$} & & \multirow[t]{2}{*}{$\checkmark$} & $1-5 \%$ & $<1 \mathrm{hr}$ & $\mathrm{hMSC}^{\mathrm{a}}$ & 24 & Partlow et al. (2014) \\
\hline & & & $16 \%$ & $5-36 \mathrm{~min}$ & ATDC-5 and HeLa & 14 & Yan et al. (2016) \\
\hline Mushroom tyrosinase & & $\checkmark$ & $8 \%$ (with $15 \%$ gelatin) & $30 \mathrm{~min}$ & $\mathrm{hMSC}^{\mathrm{a}}$ & 21 & Das et al. (2015) \\
\hline Hydroxypropylcellulose & & $\checkmark$ & $10 \%$ of blends & 30 min-1 day & L929 & $<1$ & $\begin{array}{l}\text { Gong, Yang, Ren, Chen, } \\
\text { and Shao (2012) }\end{array}$ \\
\hline
\end{tabular}

Abbreviation: SF, silk fibroin.

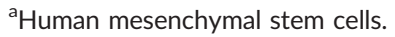

${ }^{\mathrm{b}}$ Human neural stem cells.

'Bone marrow-derived mesenchymal stem cells.

NIH/3T3, proliferated normally while encapsulated, confirming the cytocompatibility of the developed hydrogels and the feasibility of the encapsulation procedure. However, the growth rates of both cells were lower than 2D culture on tissue culture plates. It is possible that SF extracted from Bombyx mori cocoons does not possess enough cell adhesion motifs to support and enhance cell attachment. Furthermore, some studies reported a higher population of cells in G0/G1 phase when cultured in a $3 \mathrm{D}$ environment. Therefore, cells in the quiescence state undergo slower proliferation rate but remain viable when compared with 2D culture (Ravi et al., 2015).

Conversely, an inhibition in the growth of cancer-derived cell lines was observed. Indeed, encapsulated SaOS-2 did not proliferate after 7 days of culture but remained viable up to 21 days. The low proliferation of osteoblast-like cells was probably affected by the mechanical properties as well as the microarchitecture of DMPG-SF hydrogels. Indeed, cells present different sensitivities to physical, mechanical, chemical, and biological properties of the engineered biomaterials with which they are in contact. Several reports demonstrated that, for instance, the spreading and morphology of cells are related with the surface properties of the culture materials (Boyan, Hummert, Dean, \& Schwartz, 1996; McBeath, Pirone, Nelson, Bhadriraju, \& Chen, 2004). Therefore, encapsulated SaOS-2 in the hydrogels might maintain their round shape, and their growth could be unfavourable in these environments. For CaSki, their growth decreased with the increase of DMPG concentration. These distinct cellular responses to the DMPG-induced SF matrices are quite intriguing and will be further investigated.

As the cytocompatibility of SF has been well reported (Tungtasana et al., 2010) and DMPG is a naturally occurring compound in mammals (Buckland \& Wilton, 2000), our developed in situ hydrogels, as expected, did not show any harmful effect over the encapsulated L929 and NIH/3T3 cells. Moreover, L929 cells maintained their round morphology along the culture period, which it is generally observed in hydrogel systems. These results demonstrate the potential of DMPGinduced SF hydrogels as cell carrier systems for several biomedical applications, such as an in vitro pharmacologic testing model or for tissue regeneration.

In summary, this study developed a new hydrogel based on SF and DMPG and described the potential mechanism of gelation. The hydrogel formulation was optimized to significantly reduce the gelation time. Indeed, the hydrogel formation was accelerated by DMPG, which induced conformational transitions of SF from unordered conformations to the more thermodynamically stable beta sheet structure. The electrostatic and hydrophobic interactions between DMPG and SF are proposed as the primary mechanisms for unfolding the polypeptide chains from the random association and rearrangement to highly ordered structures. The biological tests demonstrated the cytocompatibility of the DMPG-SF hydrogels, presenting very high cell viability during 21 days of culture. Therefore, our results show that the developed SF-based hydrogels are strong candidates for 3D cell culture to be used in a variety of biomedical applications, including cell-based therapies and tissue regeneration.

\section{ACKNOWLEDGEMENTS}

This paper was supported by the REMIX Project, funded by the European Union's Horizon 2020 Research and Innovation programme under the Maria Sklodowska-Curie Grant agreement n. 778078. Financial support is acknowledged from Chulalongkorn Academic Advancement into Its 2nd Century (CUAASC), SPARTAN project (PTDC/CTM- 
$\mathrm{BIO} / 4388 / 2014)$, and NORTE 2020 Structured Project within the R\&D\&I Structured Project, cofunded by Norte2020-Programa Operacional Regional do Norte. Chavee Laomeephol was awarded with The 100th Anniversary Chulalongkorn University Fund for his Doctoral Scholarship and The 90th Anniversary Chulalongkorn University Fund (Ratchadaphiseksomphot Endowment Fund). Marta Guedes acknowledges the Portuguese Foundation for Science and Technology for her PhD Grant (PD/BD/113795/2015).

\section{CONFLICT OF INTEREST}

The authors have no conflicts of interest to declare.

\section{ORCID}

Nuno M. Neves (iD) https://orcid.org/0000-0003-3041-0687

\section{REFERENCES}

Altman, G. H., Diaz, F., Jakuba, C., Calabro, T., Horan, R. L., Chen, J., ... Kaplan, D. L. (2003). Silk-based biomaterials. Biomaterials, 24(3), 401-416. https://doi.org/10.1016/S0142-9612(02)00353-8

Ayub, Z. H., Arai, M., \& Hirabayashi, K. (1993). Mechanism of the gelation of fibroin solution. Bioscience, Biotechnology, and Biochemistry, 57(11), 1910-1912. https://doi.org/10.1271/bbb.57.1910

Bañuelos, S., \& Muga, A. (1996). Structural requirements for the association of native and partially folded conformations of $a$-lactalbumin with model membranes. Biochemistry, 35(13), 3892-3898. https://doi.org/ 10.1021/bi951468v

Bergers, J. J., Vingerhoeds, M. H., van Bloois, L., Herron, J. N., Janssen, L. H., Fischer, M. J., \& Crommelin, D. J. (1993). The role of protein charge in protein-lipid interactions. $\mathrm{pH}$-dependent changes of the electrophoretic mobility of liposomes through adsorption of water-soluble, globular proteins. Biochemistry, 32(17), 4641-4649. https://doi.org/ 10.1021/bi00068a023

Boyan, B. D., Hummert, T. W., Dean, D. D., \& Schwartz, Z. (1996). Role of material surfaces in regulating bone and cartilage cell response. Biomaterials, 17(2), 137-146. https://doi.org/10.1016/0142-9612(96)85758-9

Buckland, A. G., \& Wilton, D. C. (2000). Anionic phospholipids, interfacial binding and the regulation of cell functions. Biochimica et Biophysica Acta (BBA) - Molecular and Cell Biology of Lipids, 1483(2), 199-216. https://doi.org/10.1016/S1388-1981(99)00188-2

Calabrese, R., Raia, N., Huang, W., Ghezzi, C. E., Simon, M., Staii, C., ... Kaplan, D. L. (2017). Silk-ionomer and silk-tropoelastin hydrogels as charged three-dimensional culture platforms for the regulation of hMSC response. Journal of Tissue Engineering and Regenerative Medicine, 11(9), 2549-2564. https://doi.org/10.1002/term.2152

Carvalho, A. F., Gasperini, L., Ribeiro, R. S., Marques, A. P., \& Reis, R. I. (2018). Control of osmotic pressure to improve cell viability in cellladen tissue engineering constructs. Journal of Tissue Engineering and Regenerative Medicine, 12(2), e1063-e1067. https://doi.org/10.1002/ term.2432

Das, S., Pati, F., Choi, Y.-J., Rijal, G., Shim, J.-H., Kim, S. W., ... Ghosh, S. (2015). Bioprintable, cell-laden silk fibroin-gelatin hydrogel supporting multilineage differentiation of stem cells for fabrication of threedimensional tissue constructs. Acta Biomaterialia, 11(Supplement C), 233-246. https://doi.org/10.1016/j.actbio.2014.09.023

Ding, Y., Liu, W., Yu, W., Lu, S., Liu, M., Kaplan, D. L., \& Wang, X. (2018). Three-dimensional tissue culture model of human breast cancer for the evaluation of multidrug resistance. Journal of Tissue Engineering and Regenerative Medicine, 12(9), 1959-1971. https://doi.org/ 10.1002/term.2729

Dubey, P., Nawale, L., Sarkar, D., Nisal, A., \& Prabhune, A. (2015). Sophorolipid assisted tunable and rapid gelation of silk fibroin to form porous biomedical scaffolds. RSC Advances, 5(43), 33955-33962. https://doi.org/10.1039/C5RA04317D

Garidel, P., Blume, A., \& Hübner, W. (2000). A Fourier transform infrared spectroscopic study of the interaction of alkaline earth cations with the negatively charged phospholipid 1,2-dimyristoyl-sn-glycero-3phosphoglycerol. Biochimica et Biophysica Acta (BBA) - Biomembranes, 1466(1-2), 245-259. https://doi.org/10.1016/S0005-2736(00)001668

Gong, Z., Yang, Y., Ren, Q., Chen, X., \& Shao, Z. (2012). Injectable thixotropic hydrogel comprising regenerated silk fibroin and hydroxypropylcellulose. Soft Matter, 8(10), 2875-2883. https://doi. org/10.1039/C2SM06984A

Grijalvo, S., Mayr, J., Eritja, R., \& Díaz, D. D. (2016). Biodegradable liposome-encapsulated hydrogels for biomedical applications: a marriage of convenience. Biomaterials Science, 4(4), 555-574. https://doi. org/10.1039/C5BM00481K

Hamilton, D. C., Shih, H. H., Schubert, R. A., Michie, S. A., Staats, P. N., Kaplan, D. L., \& Fontaine, M. J. (2017). A silk-based encapsulation platform for pancreatic islet transplantation improves islet function in vivo. Journal of Tissue Engineering and Regenerative Medicine, 11(3), 887-895. https://doi.org/10.1002/term.1990

Hu, X., Kaplan, D., \& Cebe, P. (2006). Determining beta-sheet crystallinity in fibrous proteins by thermal analysis and infrared spectroscopy. Macromolecules, 39(18), 6161-6170. https://doi.org/10.1021/ma0610109

ISO (2009). ISO 10993 Part 1: Evaluation and testing within a risk management process. In Biological evaluation of medical devices. Switzerland.

Jones, M. N. (1992). Surfactant interactions with biomembranes and proteins. Chemical Society Reviews, 21(2), 127-136. https://doi.org/ 10.1039/CS9922100127

Kaewprasit, K., Promboon, A., Kanokpanont, S., \& Damrongsakkul, S. (2014). Physico-chemical properties and in vitro response of silk fibroin from various domestic races. Journal of Biomedical Materials Research Part B: Applied Biomaterials, 102(8), 1639-1647. https://doi.org/ 10.1002/jbm.b.33142

Kang, G.-D., Nahm, J.-H., Park, J.-S., Moon, J.-Y., Cho, C.-S., \& Yeo, J.-H. (2000). Effects of poloxamer on the gelation of silk fibroin. Macromolecular Rapid Communications, 21(11), 788-791. https://doi.org/10.1002/ 1521-3927(20000701)21:11<788::AID-MARC788>3.0.CO;2-X

Kim, U.-J., Park, J., Joo Kim, H., Wada, M., \& Kaplan, D. L. (2005). Threedimensional aqueous-derived biomaterial scaffolds from silk fibroin. Biomaterials, 26(15), 2775-2785. https://doi.org/10.1016/j. biomaterials.2004.07.044

Kim, U.-J., Park, J., Li, C., Jin, H.-J., Valluzzi, R., \& Kaplan, D. L. (2004). Structure and properties of silk hydrogels. Biomacromolecules, 5(3), 786-792. https://doi.org/10.1021/bm0345460

Lakowicz, J. (1999). Principles of Fluorescence Spectroscopy. New York, Boston, Dordrecht, London, Moscow: Kluwer Academic/Plenum Publishers.

Lee, H., Yang, G. H., Kim, M., Lee, J., Huh, J., \& Kim, G. (2018). Fabrication of micro/nanoporous collagen/dECM/silk-fibroin biocomposite scaffolds using a low temperature 3D printing process for bone tissue regeneration. Materials Science and Engineering: C, 84, 140-147. https://doi.org/10.1016/j.msec.2017.11.013

Lee, J., Cuddihy, M. J., \& Kotov, N. A. (2008). Three-dimensional cell culture matrices: state of the art. Tissue Engineering Part B: Reviews, 14(1), 61-86. https://doi.org/10.1089/teb.2007.0150

Leenhouts, J. M., van den Wijngaard, P. W. J., de Kroon, A. I. P. M., \& de Kruijff, B. (1995). Anionic phospholipids can mediate membrane 
insertion of the anionic part of a bound peptide. FEBS Letters, 370(3), 189-192. https://doi.org/10.1016/0014-5793(95)00823-R

Li, M., Ogiso, M., \& Minoura, N. (2003). Enzymatic degradation behavior of porous silk fibroin sheets. Biomaterials, 24(2), 357-365. https://doi.org/ 10.1016/S0142-9612(02)00326-5

Mano, J. F., Silva, G. A., Azevedo, H. S., Malafaya, P. B., Sousa, R. A., Silva, S. S., ... Reis, R. L. (2007). Natural origin biodegradable systems in tissue engineering and regenerative medicine: Present status and some moving trends. Journal of the Royal Society, Interface, 4(17), 999-1030. https://doi.org/10.1098/rsif.2007.0220

Matsumoto, A., Chen, J., Collette, A. L., Kim, U.-J., Altman, G. H., Cebe, P., \& Kaplan, D. L. (2006). Mechanisms of silk fibroin Sol-Gel transitions. The Journal of Physical Chemistry B, 110(43), 21630-21638. https://doi.org/ 10.1021/jp056350v

McBeath, R., Pirone, D. M., Nelson, C. M., Bhadriraju, K., \& Chen, C. S. (2004). Cell shape, cytoskeletal tension, and rhoa regulate stem cell lineage commitment. Developmental Cell, 6(4), 483-495. https://doi.org/ 10.1016/S1534-5807(04)00075-9

Nagarkar, S., Nicolai, T., Chassenieux, C., \& Lele, A. (2010). Structure and gelation mechanism of silk hydrogels. Physical Chemistry Chemical Physics, 12(15), 3834-3844. https://doi.org/10.1039/B916319K

Naskar, D., Barua, R. R., Ghosh, A. K., \& Kundu, S. C. (2014). 1 - Introduction to silk biomaterials. In Silk Biomaterials for Tissue Engineering and Regenerative Medicine (pp. 3-40). Sawston, Cambridge, UK: Woodhead Publishing.

Nogueira, E., Gomes, A. C., Preto, A., \& Cavaco-Paulo, A. (2015). Design of liposomal formulations for cell targeting. Colloids and Surfaces B: Biointerfaces, 136, 514-526. https://doi.org/10.1016/j.colsurfb.2015. 09.034

Park, J. H., Kim, M. H., Jeong, L., Cho, D., Kwon, O. H., \& Park, W. H. (2014). Effect of surfactants on sol-gel transition of silk fibroin. Journal of SolGel Science and Technology, 71(2), 364-371. https://doi.org/10.1007/ s10971-014-3379-4

Partlow, B. P., Hanna, C. W., Rnjak-Kovacina, J., Moreau, J. E., Applegate, M. B., Burke, K. A., ... Kaplan, D. L. (2014). Highly tunable elastomeric silk biomaterials. Advanced functional materials, 24(29), 4615-4624. https://doi.org/10.1002/adfm.201400526

Peppas, N. A., Hilt, J. Z., Khademhosseini, A., \& Langer, R. (2006). Hydrogels in biology and medicine: From molecular principles to bionanotechnology. Advanced Materials, 18(11), 1345-1360. https:// doi.org/10.1002/adma.200501612

Ravi, M., Paramesh, V., Kaviya, S. R., Anuradha, E., \& Solomon, F. D. P. (2015). 3D Cell culture systems: Advantages and applications. Journa of Cellular Physiology, 230(1), 16-26. https://doi.org/10.1002/ jcp.24683

Rossi, F., Santoro, M., \& Perale, G. (2015). Polymeric scaffolds as stem cell carriers in bone repair. Journal of Tissue Engineering and Regenerative Medicine, 9(10), 1093-1119. https://doi.org/10.1002/ term.1827

Snel, M. M. E., de Kroon, A. I. P. M., \& Marsh, D. (1995). Mitochondrial presequence inserts differently into membranes containing cardiolipin and phosphatidylglycerol. Biochemistry, 34(11), 3605-3613. https:// doi.org/10.1021/bi00011a015

Sun, W., Incitti, T., Migliaresi, C., Quattrone, A., Casarosa, S., \& Motta, A. (2017). Viability and neuronal differentiation of neural stem cells encapsulated in silk fibroin hydrogel functionalized with an IKVAV peptide. Journal of Tissue Engineering and Regenerative Medicine, 11(5), 1532-1541. https://doi.org/10.1002/term.2053

Tungtasana, H., Shuangshoti, S., Shuangshoti, S., Kanokpanont, S., Kaplan, D. L., Bunaprasert, T., \& Damrongsakkul, S. (2010). Tissue response and biodegradation of composite scaffolds prepared from Thai silk fibroin, gelatin and hydroxyapatite. Journal of Materials Science: Materials in Medicine, 21(12), 3151-3162. https://doi.org/10.1007/ s10856-010-4159-5

Wang, X., Kluge, J., Leisk, G. G., \& Kaplan, D. L. (2008). Sonication-induced gelation of silk fibroin for cell encapsulation. Biomaterials, 29(8), 1054-1064. https://doi.org/10.1016/j.biomaterials.2007.11.003

Wang, X., Partlow, B., Liu, J., Zheng, Z., Su, B., Wang, Y., \& Kaplan, D. L. (2015). Injectable silk-polyethylene glycol hydrogels. Acta Biomaterialia, 12, 51-61. https://doi.org/10.1016/j.actbio.2014.10.027

Wu, X., Hou, J., Li, M., Wang, J., Kaplan, D. L., \& Lu, S. (2012). Sodium dodecyl sulfate-induced rapid gelation of silk fibroin. Acta Biomaterialia, 8(6), 2185-2192. https://doi.org/10.1016/j.actbio.2012.03.007

Yan, L.-P., Silva-Correia, J., Ribeiro, V. P., Miranda-Gonçalves, V., Correia, C., da Silva Morais, A., ... Reis, R. L. (2016). Tumor growth suppression induced by biomimetic silk fibroin hydrogels. Scientific Reports, 6 , 31037. https://doi.org/10.1038/srep31037

Yin, Z., Wu, F., Xing, T., Yadavalli, V. K., Kundu, S. C., \& Lu, S. (2017). A silk fibroin hydrogel with reversible sol-gel transition. RSC Advances, 7(39), 24085-24096. https://doi.org/10.1039/C7RA02682J

Yucel, T., Cebe, P., \& Kaplan, D. L. (2009). Vortex-induced injectable silk fibroin hydrogels. Biophysical Journal, 97(7), 2044-2050. https://doi. org/10.1016/j.bpj.2009.07.028

Zhang, F., Li, J., Zhu, T., Zhang, S., Kundu, S. C., \& Lu, S. (2015). Potential of biocompatible regenerated silk fibroin/sodium $\mathrm{N}$-lauroyl sarcosinate hydrogels. Journal of Biomaterials Science, Polymer Edition, 26(12), 780-795. https://doi.org/10.1080/09205063.2015.1058576

Zhang, F. L., Jiaojiao, Zhu, T., Zhang, S., Kundu, S. C., \& Lu, S. (2015). Potential of biocompatible regenerated silk fibroin/sodium $\mathrm{N}$-lauroyl sarcosinate hydrogels. Journal of Biomaterials Science, Polymer Edition, 26(12), 780-795. https://doi.org/10.1080/09205063.2015.1058576

Zhang, X., \& Keiderling, T. A. (2006). Lipid-induced conformational transitions of $\beta$-lactoglobulin. Biochemistry, 45(27), 8444-8452. https://doi. org/10.1021/bi0602967

Zhou, C.-Z., Confalonieri, F., Jacquet, M., Perasso, R., Li, Z.-G., \& Janin, J. (2001). Silk fibroin: Structural implications of a remarkable amino acid sequence. Proteins: Structure, Function, and Bioinformatics, 44(2), 119-122. https://doi.org/10.1002/prot.1078

\section{SUPPORTING INFORMATION}

Additional supporting information may be found online in the Supporting Information section at the end of the article.

Data S1 Indirect cytotoxicity assessment of DMPG-SF hydrogels

Data S2 Growth curves of the cell lines on 2D substrates

Table S1. Cell attachment at $6 \mathrm{~h}$ after seeding, specific growth rate $(\mu$, $\mathrm{h}^{-1}$ ) and population doubling time (PDT, h) of the cell lines used in the biological experiments.

Figure S1. FTIR spectrum of the amide I region $\left(1725-1575 \mathrm{~cm}^{-1}\right)$, obtained every $10 \mathrm{~min}$, for the mixture of (A) $5 \mathrm{mM}$, (B) $10 \mathrm{mM}$, and (C) $15 \mathrm{mM}$ DMPG-3\% SF. (D) Absorbance spectrum after deconvolution with contributing peaks. Peak location corresponding to the secondary structures was indicated.

Figure S2. Complex modulus (G*) of 5, 10 and 15 mM DMPG-3\% SF obtained from time sweep experiments. Frequency, strain and temperature were fixed at $1 \mathrm{~Hz}, 0.5 \%$ and $37^{\circ} \mathrm{C}$, respectively. 
Figure S3. Viability (\%) of L929 cultured in the absence (DMEM/10\% FBS; negative control) or in the presence different dilutions of extracts obtained from 5, 10, and 15 mM DMPG-3\% SF hydrogels. A positive control (DMEM+Zn acetate) and a reference (serum-free DMEM) were also tested. The dash line indicates 70\% viability (ISO 10993-5:2009).

Figure S4. Morphology of L929 cells after $24 \mathrm{~h}$ of culture with the extracts of 5, 10, 15 mM DMPG-3\% SF hydrogel, serum-free DMEM, DMEM/10\% FBS and DMEM containing 20 ppm zinc acetate. The images were obtained from phase-contrast microscope at $20 x$ magnification.
Figure S5. Growth curves of the cell lines used in the biological experiments, namely L929 (A), NIH/3T3 (B), SaOS-2 (C), and CaSki (D). Cells were plated with a density of 10,000 cells $/ \mathrm{cm}^{2}$. The number of cells was determined by MTT assay using a standard curve of absorbance versus cell number.

How to cite this article: Laomeephol C, Guedes M, Ferreira H, et al. Phospholipid-induced silk fibroin hydrogels and their potential as cell carriers for tissue regeneration. J Tissue Eng

Regen Med. 2019;1-13. https://doi.org/10.1002/term.2982 